\title{
Refractive Index and Transmittance Optimization of C-S-Au Film by Plasma Process
}

\author{
Md. Abul Kashem, Masaki Matushita, and Shinzo Morita \\ Department of Electronics, Graduate School of Engineering, Nagoya University \\ Nagoya 464-8603, Japan \\ E-mail:m-kashem@echo.nuee.nagoya-u.ac.jp
}

\begin{abstract}
Carbon-sulfur-gold (C-S-Au) film was formed by co-operation process of plasma $\mathrm{CVD}$ and sputtering with using methane, $\mathrm{SF}_{6}$ and $\mathrm{Ar}$ mixture gas and gold plate discharge electrode. After optimization, $51 \%$ of transmittance at around $500 \mathrm{~nm}$ and 3.5 of refractive index was realized at a gas flow rate of 10,10 and $15 \mathrm{SCCM}$ for methane, $\mathrm{SF}_{6}$ and $\mathrm{Ar}$ respectively, a pressure of 0.1 Torr and a discharge power of $100 \mathrm{~W}$. The large refractive index was referred to atomically distributed gold atom in the C-S-Au film.
\end{abstract}

Key Words: RF Plasma CVD, Sputtering, C-S-Au Film, Gold, Refractive Index, Optical transmittance.

\section{Introduction}

Photonic crystal is expected to be very useful material for optical devices like as optical wave-guide and others [1]. To fabricate these kinds of devices, highly transparent and large refractive index material is useful. $\mathrm{GaAs}, \mathrm{SiO}_{2}$ and other compounds are utilizing as the large refractive index materials [2,3]. However we proposed a new material for the same application, which is composed of $C, S$, and $A u$ atom, where $C$ and $\mathrm{S}$ atoms form volatile materials with oxygen in the etching process of oxygen plasma. Au atom content in the film is a few percent. Because of the small content, $\mathrm{Au}$ atom will not affect on the process largely even if gold is chemically inert material. Whereas, our proposed film is expected to be good process compatibility.

Gold containing carbonaceous film is reported to be a relatively large refractive index material $[4,5]$. The maximum value of 2.7 at around $700 \mathrm{~nm}$ was reported for fluorinated polymer with $\mathrm{Au}$ clusters. Where the mechanism of gold mixing was referred to sputtering gold plate upper electrode caused on a negative self-bias potential with respect to plasma during the polymerization. Our aim is to increase the refractive index of C-S film by introducing gold atom under the cooperation process of plasma CVD and sputtering, because C-S film is known as a large refractive index material. The film was named as C-S-Au film and the refractive index was increased to 3.7 [6]. However, the film was colored in red, therefore the absorption in the visible light wavelength range was expected to be large compared to the amorphous carbon ( $\mathrm{a}-\mathrm{C})$ film.

In this work the refractive index and optical transmittance of C-S-Au film in the visible light wavelength range was aimed to be optimized for the optical devises at around $500 \mathrm{~nm}$ wavelength region.

\section{Experimental}

The film was formed by co-operation process of plasma CVD with using methane, $\mathrm{SF}_{6}$ and $\mathrm{Ar}$ mixture gas and sputtering of gold plate on the discharge electrode with using a plasma CVD reactor, which has a parallel plate electrode of $20 \mathrm{~cm}$ diameter and $1.5 \mathrm{~cm}$ gap distance between the two electrodes. The upper electrode was made of graphite and connected to RF power source. A gold plate with area of $50 \times 50 \mathrm{~mm}^{2}$ was set on the upper electrode. The reactive gas was introduced from the upper discharge electrode through the numerous small holes on the electrode. Substrates of Si wafer and glass plate were set up on the lower discharge electrode grounded and electrically connected to the reactor vessel of stainless steel.

The RF discharge frequency was $13.56 \mathrm{MHz}$. A discharge pressure of 0.1 Torr, a discharge power of 100 $\mathrm{W}$, and discharge duration of $30 \mathrm{~min}$ were kept to be constant during the deposition for all the samples. Methane $\left(\mathrm{CH}_{4}\right), \mathrm{Ar}$ and $\mathrm{SF}_{6}$ mixture gas was used for film deposition. The flow rate of methane $\left(\mathrm{CH}_{4}\right)$ was kept constant to be $10 \mathrm{SCCM}$, but the flow rate of $\mathrm{SF}_{6}$ was as $0,15,20$ and $25 \mathrm{SCCM}$ and the Ar flow rate 
was varied from 2 to 25 SCCM. The deposited films were characterized by measuring the thickness by roughness meter, the refractive index using ellipsometer at the wavelength of $633 \mathrm{~nm}$, the atomic compositions by ESCA apparatus, the optical transmittance by spectro-photometer and the X-ray diffraction by $\mathrm{CuK}_{\alpha}$ XRD apparatus.

\section{Results and Discussions}

Optical transmittance spectra of a-C, C-S and C-S-Au are shown in Fig.1. The samples were formed by using following gas parameters: both the $\mathrm{CH}_{4}$ and Ar flow rate were 10 SCCM for all the films, where flow rate of $\mathrm{SF}_{6}$ was $25 \mathrm{SCCM}$ for the C-S and C-S-Au film and the discharge pressure was kept constant from about 0.08 to 0.09 Torr for this sample fabrication. The maximum $\mathrm{S}$ atom density was 20 atomic $\%$ for C-S film and the $S$ and Au density of C-S-Au film was 18.7 and 0.1 atomic \% respectively. Both the C-S and C-S-Au film showed large absorption at short wavelength range with respect to the $\mathrm{a}-\mathrm{C}$ film. In order to confirm the effect of sulfur and gold atom on the transmittance, new films were fabricated by changing the $\mathrm{SF}_{6}$ flow rate as $0,15,20$ and $25 \mathrm{SCCM}$.

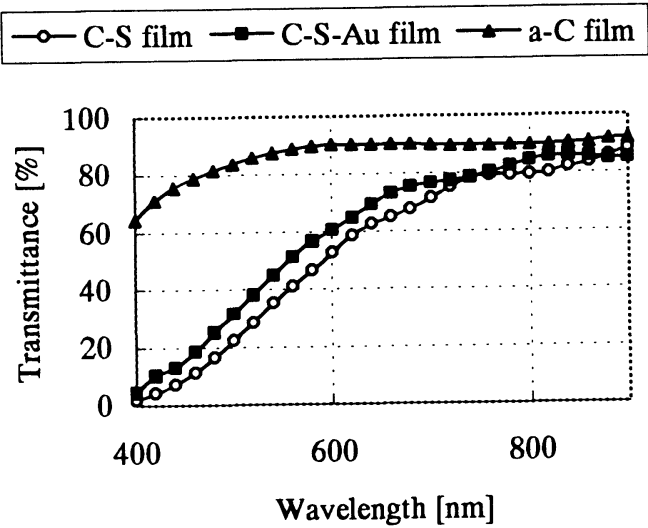

Fig.1. Optical transmittance of C-S, C-S-Au and a-C film as a function of wavelength.

For the $\mathrm{SF}_{6}$ flow rate of $0 \mathrm{SCCM}$ and Ar flow rate from 2 to 25 SCCM, thickness of films was distributed from 350 to $700 \mathrm{~mm}$. As shown in Table 1, the atomic compositions of the bulk were measured by ESCA measurements after Ar plasma sputtering in the ESCA apparatus. Oxygen (O) was not included in the source gas but oxygen was detected by the ESCA measurements. Probably the oxygen was referred to the contaminated oxide when the sample was exposed to the air and/or the leaked oxide gases during the deposition. However, the oxygen atom contents were merely 0.1 or 0.0 atomic $\%$ for the samples formed at each Ar flow rate, whereas the effect of oxygen on the properties will be neglected. The maximum 5.5 atomic \% of gold was realized at 15 SCCM of Ar flow rate.

Table. 1. Atomic composition of the C-Au film

\begin{tabular}{|c|c|c|c|}
\hline \multirow{2}{*}{$\begin{array}{c}\text { Flow of Ar. } \\
\text { (SCCM) }\end{array}$} & \multicolumn{3}{|c|}{ Chemical composition } \\
\cline { 2 - 4 } & $\mathrm{C}(\%)$ & $\mathrm{Au}(\%)$ & $\mathrm{O}(\%)$ \\
\hline 2 & 98.2 & 1.7 & 0.1 \\
\hline 5 & 97.8 & 2.2 & 0.0 \\
\hline 10 & 97.3 & 2.4 & 0.1 \\
\hline 15 & 94.5 & 5.5 & 0.0 \\
\hline 20 & 95.8 & 4.2 & 0.0 \\
\hline 25 & 97.5 & 2.4 & 0.1 \\
\hline
\end{tabular}

As shown in Fig. 2, the refractive index of C-Au film was increased monotonically from 1.9 to 3.1 with increasing the Ar flow rate from 2 to 15 SCCM, however further increase of Ar flow rate caused decrease of the refractive index. Atomic \% of gold also plotted in the same figure with refractive index as a function of Ar flow rate. Both the gold content and the refractive index showed the maximum value at 15 SCCM of Ar flow rate. Increase of the refractive index will be referred mainly to the content of gold atom.

For 15,20 and $25 \mathrm{SCCM}$ of $\mathrm{SF}_{6}$ flow rate, the atomic compositions were measured as shown in Table 2, 3 and 4 respectively. $F$ and $O$ atom density were measured as 0.0-0.7 and 0.0-1.7 atomic \% respectively which are not so small compared to Au atomic \%. The origin of $\mathrm{F}$ atom in the film was referred to the remaining after the decomposition of $\mathrm{SF}_{6}$ with methane glow discharge by forming HF [7].

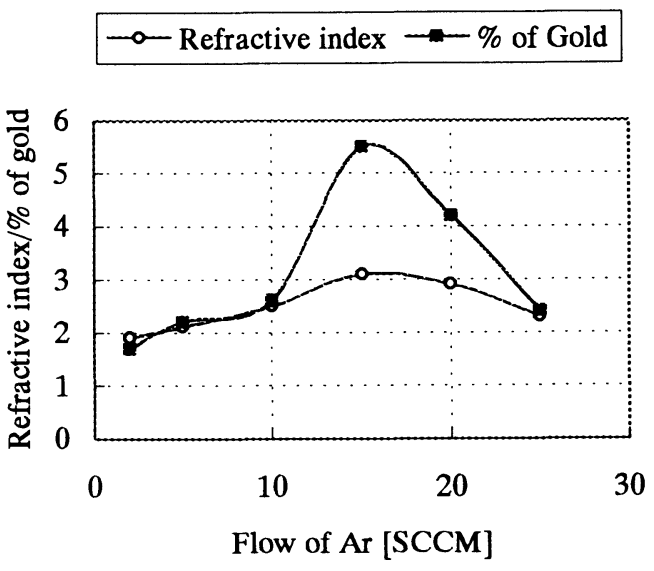

Fig.2. Refractive index and atomic $\%$ of gold as a function of Ar flow rate.

According to the theory of dielectrics, electronic polarizibility of $\mathrm{F}$ and $\mathrm{O}$ is not so lange compared to $\mathrm{Au}$. 
Whereas the effect of $\mathrm{F}$ and $\mathrm{O}$ on the refractive index will be neglected here. With increasing $\mathrm{SF}_{6}$ flow rate, sulfur and $\mathrm{Au}$ atom density showed a tendency to increase in the film. However, the gold atom density was smaller than that where the $\mathrm{SF}_{6}$ flow rate was 0 $\mathrm{SCCM}$. In the mixture gas of methane, $\mathrm{SF}_{6}$ and $\mathrm{Ar}, \mathrm{Au}$ atom density in the deposited film was however increasing with increasing $\mathrm{SF}_{6}$ flow rate. The variation of $\mathrm{Au}$ content in this experiment will be explained as followings. Au atom are sputtered during the plasma CVD process of mixture gas, but the sputtering was suppressed under the mixture gas with $\mathrm{SF}_{6}$. However $\mathrm{SF}_{6}$ gas is supposed to enhance the sputtering chemically.

Table 2. Atomic composition of the C-S-Au film $\left(\mathrm{CH}_{4}: 10 \mathrm{SCCM}, \mathrm{SF}_{6}\right.$ : 15 SCCM, Pressure: 0.1 Torr.)

\begin{tabular}{|c|c|c|c|c|c|}
\hline $\begin{array}{c}\text { Flow of } \\
\mathrm{Ar} \\
(\mathrm{SCCM})\end{array}$ & $\begin{array}{c}\mathrm{C} \\
(\%)\end{array}$ & $\begin{array}{c}\mathrm{S} \\
(\%)\end{array}$ & $\begin{array}{c}\mathrm{Au} \\
(\%)\end{array}$ & $\begin{array}{c}\mathrm{F} \\
(\%)\end{array}$ & $\begin{array}{c}\mathrm{O} \\
(\%)\end{array}$ \\
\hline 2 & 90.2 & 7.2 & 0.8 & 0.2 & 1.6 \\
\hline 5 & 88.4 & 8.8 & 1.1 & 0.0 & 1.7 \\
\hline 10 & 90.8 & 6.2 & 1.9 & 0.2 & 0.9 \\
\hline 15 & 90.6 & 6.3 & 1.8 & 0.0 & 1.3 \\
\hline 20 & 90.1 & 7.6 & 0.7 & 0.1 & 1.5 \\
\hline 25 & 91.1 & 7.1 & 0.6 & 0.0 & 1.3 \\
\hline
\end{tabular}

Table3. Atomic composition of the C-S-Au film $\left(\mathrm{CH}_{4}: 10\right.$ SCCM, $\mathrm{SF}_{6}: 20 \mathrm{SCCM}$, Pressure: 0.1 Torr.)

\begin{tabular}{|c|c|c|c|c|c|}
\hline $\begin{array}{c}\text { Flow of } \\
\mathrm{Ar} \\
(\mathrm{SCCM})\end{array}$ & $\begin{array}{c}\mathrm{C} \\
(\%)\end{array}$ & $\begin{array}{c}\mathrm{S} \\
(\%)\end{array}$ & $\begin{array}{c}\mathrm{Au} \\
(\%)\end{array}$ & $\begin{array}{c}\mathrm{F} \\
(\%)\end{array}$ & $\begin{array}{c}\mathrm{O} \\
(\%)\end{array}$ \\
\hline 2 & 91.8 & 7.1 & 0.8 & 0.1 & 0.2 \\
\hline 5 & 87.5 & 10.7 & 1.1 & 0.0 & 0.7 \\
\hline 10 & 86.2 & 12.6 & 1.2 & 0.0 & 0.0 \\
\hline 15 & 90.3 & 8.2 & 0.9 & 0.2 & 0.4 \\
\hline 20 & 91.0 & 7.4 & 1.5 & 0.1 & 0.0 \\
\hline 25 & 92.3 & 6.5 & 0.8 & 0.0 & 0.4 \\
\hline
\end{tabular}

Table 4. Atomic composition of the C-S-Au film $\left(\mathrm{CH}_{4}: 10\right.$ SCCM, SF 6 : 25 SCCM, Pressure: 0.1 Torr.)

\begin{tabular}{|c|c|c|c|c|c|}
\hline $\begin{array}{c}\text { Flow of } \\
\mathrm{Ar} \\
(\mathrm{SCCM})\end{array}$ & $\begin{array}{c}\mathrm{C} \\
(\%)\end{array}$ & $\begin{array}{c}\mathrm{S} \\
(\%)\end{array}$ & $\begin{array}{c}\mathrm{Au} \\
(\%)\end{array}$ & $\begin{array}{c}\mathrm{F} \\
(\%)\end{array}$ & $\begin{array}{c}\mathrm{O} \\
(\%)\end{array}$ \\
\hline 2 & 90.1 & 7.9 & 1.1 & 0.3 & 0.6 \\
\hline 5 & 86.4 & 10.1 & 2.5 & 0.4 & 0.6 \\
\hline 10 & 81.6 & 15.1 & 2.8 & 0.3 & 0.2 \\
\hline 15 & 85.4 & 13.7 & 1.4 & 0.7 & 0.8 \\
\hline 20 & 85.2 & 12.1 & 1.2 & 0.1 & 1.4 \\
\hline 25 & 86.2 & 11.9 & 1.4 & 0.1 & 0.4 \\
\hline
\end{tabular}

Figure 3 shows the refractive indexes of the films formed at a $\mathrm{SF}_{6}$ flow rate of $0,15,20$ and $25 \mathrm{SCCM}$ as a function of $\mathrm{Ar}$ flow rate. For all experimental results, there is one peak in refractive index data plotted as a function of $\mathrm{Ar}$ flow rate for each $\mathrm{SF}_{6}$ flow rate. For 20 and $25 \mathrm{SCCM}$ of $\mathrm{SF}_{6}$ flow rate, the peak was observed at 10 SCCM of Ar flow rate, but the peak was shifted to $15 \mathrm{SCCM}$ of Ar flow rate for 0 and $15 \mathrm{SCCM}_{\text {of }} \mathrm{SF}_{6}$ flow rate and the peak value was slightly decreased. The maximum value of refractive index was measured as 3.6 at a flow rate of 25 and 10 $\mathrm{SCCM}$ for $\mathrm{SF}_{6}$ and $\mathrm{Ar}$ respectively, where $\mathrm{S}$ and $\mathrm{Au}$ atom density showed the maximum value in the four experimental data as shown in Table 2,3 and 4.

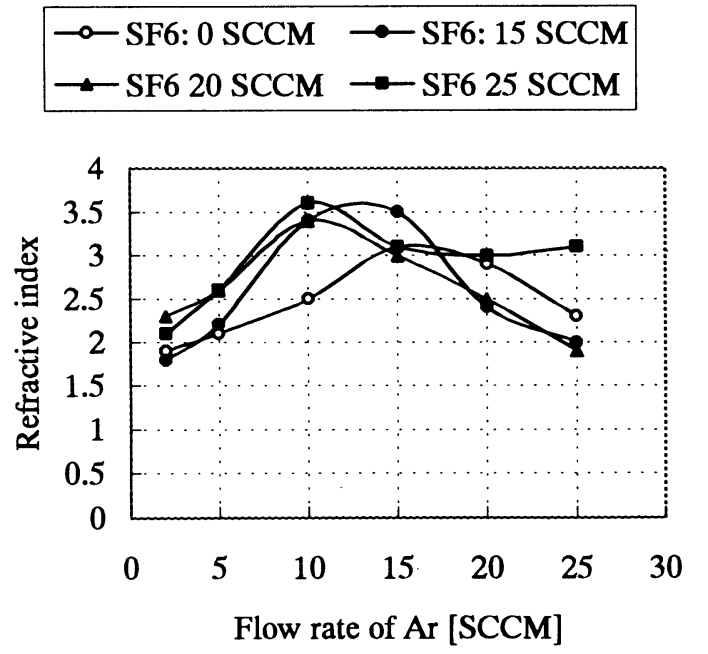

Fig. 3. Refractive index as a function of Ar flow rate

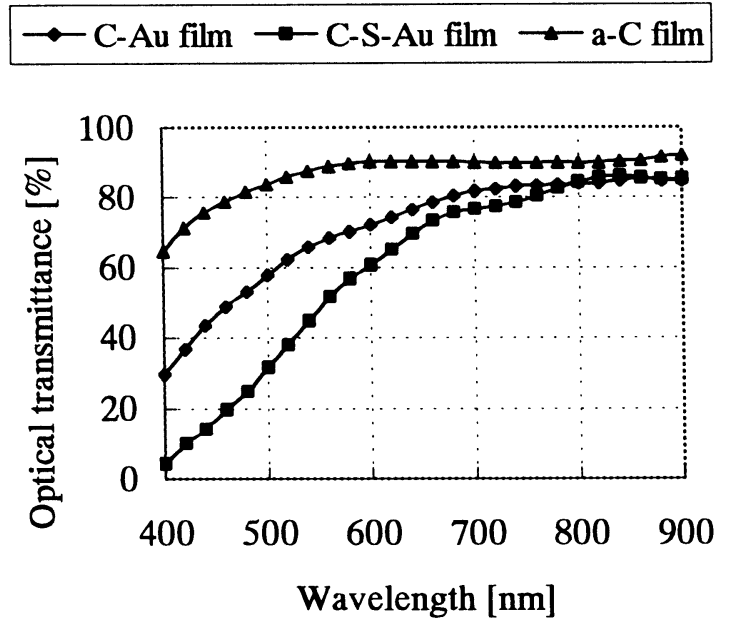

Fig. 4. Optical transmittance of C-Au, C-S-Au and a-C film as a function of wavelength

For the three samples, optical transmittance data are plotted in Fig. 4 as a function of wavelength, where the a-C film is same as Fig. 1, C-Au and C-S-Au films 
are the same films as that the refractive index values were the maximum in Fig. 3. By eliminating sulfur atom, the transmittance of $\mathrm{C}$-Au film was increased relatively compared to the C-S-Au film in the short wave length region, but the transmittance was still small compared to the a-C film. Therefore, both the sulfur and gold atom is considered to be responsible for the absorption in the short wavelength region.

Figure 5 represents the refractive index of the films as a function of $\mathrm{SF}_{6}$ flow rate for Ar flow rate of 10 and 15 SCCM. For 10 SCCM of Ar flow rate, the refractive index was increasing with increasing $\mathrm{SF}_{6}$ flow rate, however, for 15 SCCM of Ar flow rate the refractive index showed a peak at $15 \mathrm{SCCM}$ of $\mathrm{SF}_{6}$ flow rate.

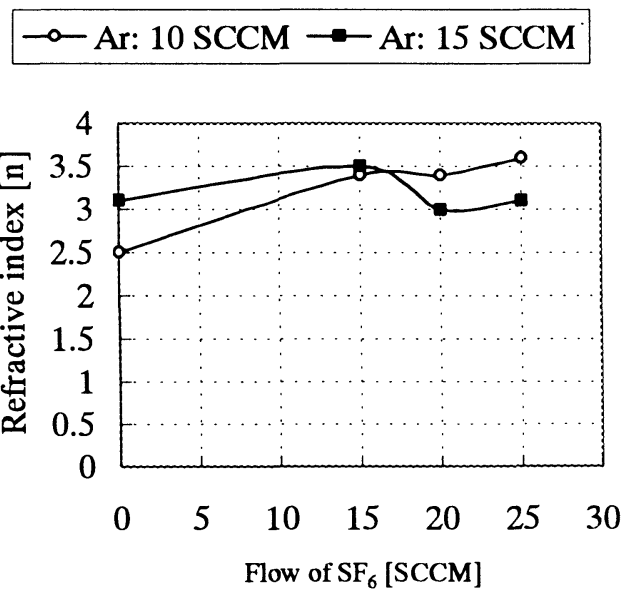

Fig. 5. Refractive index as a function of $\mathrm{SF}_{6}$ flow rate

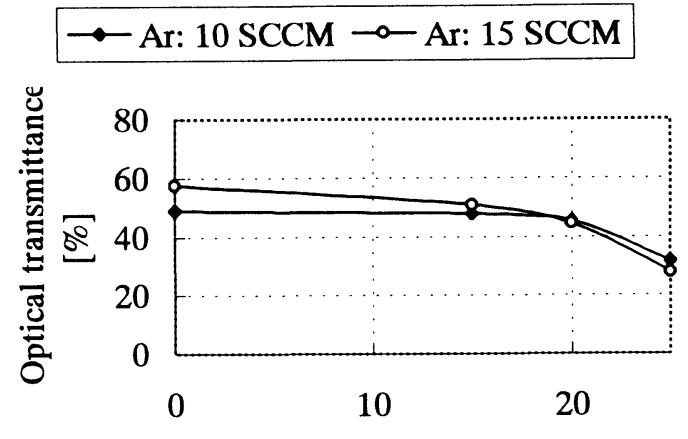

Flow rate of $\mathrm{SF}_{6}[\mathrm{SCCM}]$

Fig. 6. Optical transmittance of C-S-Au films at 500 nm.

For the C-S-Au films, the optical transmittance data were plotted as a function of $\mathrm{SF}_{6}$ flow rate for 10 and 15 SCCM of Ar flow rate as shown in Fig. 6. The optical transmittance was decreased monotonically with increasing $\mathrm{SF}_{6}$ flow rate. This fact means that the optical transmittance was decreased with increasing the $\mathrm{S}$ atom density in the film because the $\mathrm{S}$ atom density in the film is increasing with increasing the $\mathrm{SF}_{6}$ flow rate.

From the figure 5 and 6 , the maximum refractive index of 3.6 was observed at $10 \mathrm{SCCM} \mathrm{Ar}$ flow rate and $25 \mathrm{SCCM}$ of $\mathrm{SF}_{6}$ flow rate but optical transmittance is smallest at this condition. On the other hand, the maximum transmittance was observed at 15 SCCM of Ar flow rate and $0 \mathrm{SCCM}$ of $\mathrm{SF}_{6}$ flow rate but refractive index is not so large at this condition. The optimized transmittance and refractive index value were observed to be about $51 \%$ at an optical wavelength of $500 \mathrm{~nm}$ and 3.5 respectively at a flow rate of $15 \mathrm{SCCM}$ for both $\mathrm{Ar}$ and $\mathrm{SF}_{6}$. Sulfur and gold atom density at the optimized condition were 6.3 and 1.8 atomic \% respectively.

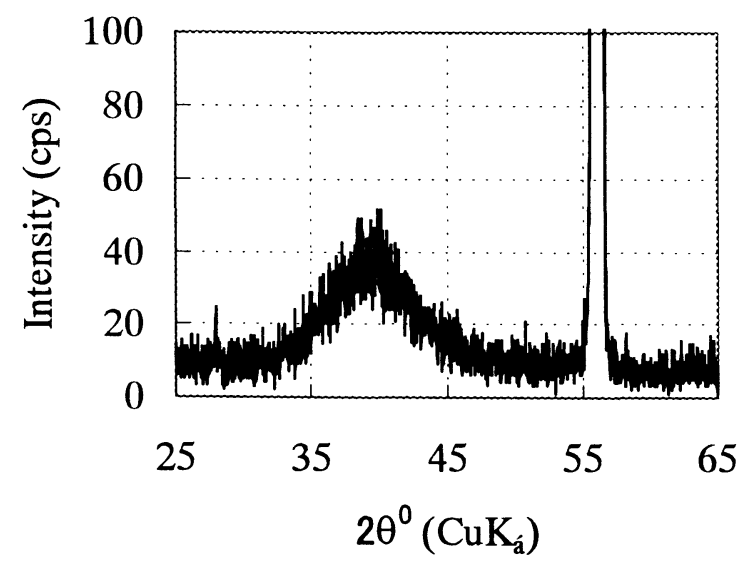

Fig 7. X-ray diffraction pattern of C-Au film

The maximum gold atom density of C-Au film was 5.5 atomic \% but the refractive index was 3.1. However Martinu reported 2.9 as the refractive index at 25 volume \% of gold at a wavelength of $700 \mathrm{~nm}$ in the fluorinated film [4]. The reason of small refractive index for the large $\mathrm{Au}$ content is expected as following. The gold cluster is conductive and behaves like as a large atom because the gold atom electronic polarizability was muffled with the electron cloud in the conducting cluster.

To investigate the $\mathrm{Au}$ atom distribution in the film, X-ray diffraction measurement was carried out with using $\mathrm{CuK}_{\alpha}$ radiation source as shown in Fig. 7.

Diffraction peaks for the C-Au film at 5.5 atomic \% of $\mathrm{Au}$ in Table 1 were compared with those of standard compounds reported in the JCPDS data file. Peak at $2 \theta=56.2^{\circ}$ is referred to $\mathrm{Si}$ wafer but wide peak at $2 \theta=39.4^{0}$ is referred to the amorphous carbon 
and gold, where the peaks of carbon and gold are not resolved because they are located at the closed position. No crystalline gold peak was confirmed in the diffraction spectrum. The gold is known as chemically inert material but it also known to form week chemical bond with other atom like sulfur, oxygen, and others [8]. The atomic distribution of $\mathrm{Au}$ atom in the C-S-Au film will be referred to the above chemical bond.

From the refractive index values by an ellipsometer at $633 \mathrm{~nm}$, the electronic polarizability can be calculated if the optical absorption can be neglected [9]. With using diamond data, carbon electronic polarizibility $\left(\alpha_{\mathrm{C}}\right)$ can be calculated to be $93.4 \times 10^{-42}$ $\left[\mathrm{Fm}^{2}\right], \mathrm{C}$ atom number per unit volume in amorphous carbon film is obtained as $97.3 \times 10^{27}\left[1 / \mathrm{m}^{3}\right]$ with using 1.6 of refractive index for amorphous carbon. The density of amorphous carbon was almost half compared to the diamond. With using Table 1 to 4 data and under the assumption that atom densities of $\mathrm{a}-\mathrm{C}$, $\mathrm{C}-\mathrm{Au}$ and C-S-Au are same, the electronic polarizibility of gold $\left(\alpha_{\mathrm{Au}}\right)$ and sulfur $\left(\alpha_{\mathrm{S}}\right)$ were calculated to be 2575 and 550 to $760 \times 10^{-42}\left[\mathrm{Fm}^{2}\right]$ respectively. The evaluated values in the previous paper for $\alpha_{\mathrm{Au}}$ and $\alpha$ $s$ were 57830 and $460 \times 10^{-42}\left[\mathrm{Fm}^{2}\right]$ respectively. Because of several approximation, the $\alpha_{\mathrm{S}}$ values are consider to be almost similar, however $\alpha_{\text {Au }}$ was evaluated one order smaller value in this work. The large deviation of $\alpha_{\mathrm{Au}}$ value will be referred to the large error in measurement of gold content of previous film. Therefore $\alpha_{\mathrm{Au}}$ of $2575 \times 10^{-42}\left[\mathrm{Fm}^{2}\right]$ is consider to be reliable value.

\section{Conclusion}

The optimization of refractive index and optical transmittance of C-S-Au film was discussed in this paper. The large optical absorption in the short wavelength region at around $500 \mathrm{~nm}$ was referred to $S$ and $\mathrm{Au}$ atom content. However the large refractive index was also referred to $\mathrm{S}$ and $\mathrm{Au}$ atom in the film. Therefore, the optimized condition of transmittance and refractive index values were realized at a flow rate of 15 SCCM for both Ar and $\mathrm{SF}_{6}$ and a flow rate of 10 SCCM of methane, a pressure of 0.1 Torr, a frequency of $15.56 \mathrm{MHz}$ and a discharge power of $100 \mathrm{~W}$, where the refractive index was 3.5. The refractive index of $\mathrm{C}-\mathrm{S}-\mathrm{Au}$ was also discussed using the electronic polarizibility of $\mathrm{C}, \mathrm{S}$ and $\mathrm{Au}$ atom and the large refractive index was referred to atomically distributed $\mathrm{Au}$ atom in the film.

\section{Acknowledgements}

The works were performed partly at the Center of Co-operative Research in Advance Science and Technology (CCRAST), Nagoya University. We would like to express our thanks to Prof. N. Hayakawa, Director, CCRAST. The refractive index and optical transmittance was measured at Yasuda and Tsunashima laboratory respectively. We also express our thanks to the respective persons at the laboratories.

\section{References}

1. M.D.B. Charlton, M.E. Zoorob and G.J. Parker, Mat. Sci. Eng. B, 74 (2000) pp.17-21.

2. D. Cassagne, C. Jouanin, and D. Bertho, Phy. Rev. B 53 (11) (1996) p.7134.

3. H. Kosaka, T. Kawashima, A. Tomita et. al., Phy. Rev. B 58(16) (1998) pp.10096-10099.

4. L. Marutinu, Solar Energy Materials, 15(1987) p.21.

5. R. d'Agostino, Ed., "Plasma Deposition, Treatment, and Etching of Polymers", Academic Press, (1990).

6. M. Matsushita, Md. Abul Kashem and S. Morita; $J$. Photoplolym. Sci. and Tech., 14 (1) (2001) pp.123-126.

7. M. Matsushita, Md. Zarid. Bin Harum, Md. Abul Kashem and S. Morita; J. Photoplolym. Sci. and Tech., 12 (1) (1999) pp.11-14.

8. For example; $\mathrm{K}$. Ishikawa, T. Isonaga, S. Wakita, Y. Suzuki; Solid State Ionics, 79 (1995) pp.60-66

9. M. Matsushita, Md. Abul Kashem and S. Morita; Printing in the Thin Solid films. 